\title{
ON THE ISOTOPIC COMPOSITION OF DISSOLVED INORGANIC CARBON IN RIVERS AND SHALLOW GROUNDWATER: A DIAGRAMMATIC APPROACH TO PROCESS IDENTIFICATION AND A MORE REALISTIC MODEL OF THE OPEN SYSTEM
}

\section{B. TAYLOR}

\author{
Institute of Geological and Nuclear Sciences Ltd., P.O. Box 31-312, Lower Hutt, New Zealand
}

\begin{abstract}
Rivers and shallow groundwater are deep groundwater precursors. Their dissolved inorganic carbon content (DIC) and its isotopic composition are end members in the evolution of these properties in confined situations, and are therefore essential information when applying carbon isotopes as tracers of groundwater processes and determining aquifer residence times using ${ }^{14} \mathrm{C}$.

During studies of regional aquifer systems in New Zealand, a simple model has been developed to explain the isotopic compositions of DIC encountered in rivers and shallow groundwater. The model format incorporates a diagrammatic approach, providing a framework for tracing the subsequent evolution of DIC in both precipitation- and river-recharged aquifers under closed conditions.

DIC concentration of rivers continuously adjusts toward chemical and isotopic equilibrium between direct addition of $\mathrm{CO}_{2}$ to the water (via plant respiration and decay of dead organic material) and exchange of $\mathrm{CO}_{2}$ across the river-air interface. In the shallow groundwater situation, the gaseous reservoir is soil $\mathrm{CO}_{2}$, generally at significantly higher partial pressure. In both cases, calcite dissolution or other processes may be an additional source of DIC directly added to the bicarbonate and dissolved $\mathrm{CO}_{2}$ components; while these may add or remove DIC, steady-state isotopic concentrations are considered to be determined only by the dynamic balance between directly added $\mathrm{CO}_{2}$ and gas exchange. This model allows the calculation of steady states, using selectable parameters in river or groundwater situations. These appear as straight lines in ${ }^{13} \mathrm{C}$ or ${ }^{14} \mathrm{C} v$ v. $1 / \mathrm{DIC}$, or total ${ }^{14} \mathrm{C} v$ s. DIC plots, into which the experimental data can be inserted for interpretation. In the case of ${ }^{14} \mathrm{C}$, the steady-state balance is very often complicated by the presence of an old component in the directly added DIC; the understanding achieved via the ${ }^{13} \mathrm{C}$ patterns is helpful in recognizing this.
\end{abstract}

Data from four contrasting aquifer systems in New Zealand. The success of the approach has depended crucially on DIC concentrations measured very accurately on the isotope samples, rather than separate chemical analyses.

\section{INTRODUCTION}

The large body of data that has accumulated since the pioneer paper by Münnich (1957) demonstrates that ${ }^{14} \mathrm{C}$ concentrations of dissolved inorganic carbon (DIC) in unconfined groundwater cover a broad range, often being much lower than that of ambient atmospheric $\mathrm{CO}_{2}$. To estimate the residence time of any groundwater with accuracy, one needs to know not only the precursor ${ }^{14} \mathrm{C}$ concentration at some precisely defined time $\mathrm{t}=0$, but also whether subsequent reductions of ${ }^{14} \mathrm{C}$ concentrations were caused by chemical reactions or by radioactive decay. These two core problems of the dating method have been tackled by a quite bewildering number of chemical/isotopic models of varying degrees of complexity. It is by now well established (e.g., Fontes and Garnier 1979; Plata et al. 1984; Geyh 1991) that the application of several models to the same data set can produce an uncomfortably wide range of estimates for both precursor ${ }^{14} \mathrm{C}$ concentrations and residence times, a situation that seriously hinders acceptance of the isotope as a reliable indicator of groundwater age.

A research program applying carbon isotopes in multidisciplinary studies of regional aquifer systems in New Zealand was initiated about six years ago after routine measurements of ${ }^{14} \mathrm{C}$ by accelerator mass spectrometry became possible at this Institute. The capability to measure DIC, ${ }^{13} \mathrm{C}$ and ${ }^{14} \mathrm{C}$ on carbon recovered from water samples as small as 1 liter has greatly simplified field and laboratory procedures. From the outset, a central aim of this research has been to test a long-held suspicion that difficulties encountered in solving the two core problems might be at least partially resolved by an altogether simpler approach to the open system and more reliable identification of processes that contribute DIC. 
Stimulus towards simplification is provided by consideration of the chemical equations describing the limited range of chemical processes (see, e.g., Mook 1980) that can modify DIC concentrations in the closed phase of groundwater residence time. Additions of DIC very often carry specific ${ }^{13} \mathrm{C}$ signatures, for example through dissolution of calcite $\left(\delta^{13} \mathrm{C} \approx 0\right.$ ), or oxidation (decay) of organic material $\left(\delta^{13} \mathrm{C} \approx-25\right)$. In the case of ${ }^{14} \mathrm{C}$, these signatures are not specific if the age of the contributing material is unknown. However, additions to DIC very frequently derive from old (i.e. ${ }^{14} \mathrm{C}$-free) or very recent material. Correctly identified chemical processes obtained from ${ }^{13} \mathrm{C} v s .1 / \mathrm{DIC}$ relationships can be applied to predict equivalent relationships for ${ }^{14} \mathrm{C}$, and vice versa. Deviations between predicted and measured relationships then become essential evidence in interpreting the finer details of the chemical evolution processes, before deciding the extent of ${ }^{14} \mathrm{C}$ concentration depletion due to radioactive decay. As has been the case with other isotopes, such a diagrammatic approach is also potentially useful in recognizing mixing of groundwaters with differing chemical and isotopic compositions.

This paper briefly describes and illustrates how chemical processes in confined situations have been identified, before introducing a model framework within which carbon isotope data for precursor (open system) groundwater can be examined and more readily understood.

\section{PRELIMINARY OBSERVATIONS: TERMINOLOGY, ISOTOPIC UNITS, EXPERIMENTAL TECHNIQUES AND THE VALIDITY OF INTER-ISOTOPE CORRELATIONS}

Separate isotope modeling scenarios apply in closed and open situations. An open situation allows exchange of the isotopic tracer across a boundary, e.g., the water-air interface. In the case of shallow groundwater, "air" is the soil atmosphere, whose $\mathrm{CO}_{2}$ and ${ }^{13} \mathrm{C}$ concentrations differ appreciably from that of the free atmosphere pertaining to the case of rivers. Changes of tracer concentration in closed systems are due to purely internal sources, e.g., the dissolution of aquifer materials by weathering processes, or the addition of $\mathrm{CO}_{2}$ through decay of organic material in contact with the water.

In the hydrogeological context, aquifers are described as unconfined (with an overlying water table), confined (bounded by aquicludes), or partially confined (bounded by aquitards). The physical boundaries between unconfined and confined situations are not in general coincident with those that define open or closed tracer behavior. It is quite common for groundwater to reach a closed state for a tracer while still unconfined in the hydrogeological sense. Moreover, the converse is also true, i.e., an open tracer situation can exist in a confined aquifer; an example would be the introduction of a gas phase by the attainment of methane saturation, which would incorporate some dissolved $\mathrm{CO}_{2}$ and facilitate its migration.

In the strictest sense, groundwater residence time may be considered to accumulate during both open and closed phases. However, exchange processes under open conditions completely disable ${ }^{14} \mathrm{C}$ as an age indicator for that phase of the total residence time. Hence groundwater residence times using ${ }^{14} \mathrm{C}$ can only be established for the closed phase. The appropriate chemical and isotopic precursor concentrations are therefore those which pertain at the time of the open-to-closed transition.

If processes affecting DIC are to be discerned by observing changes of isotopic composition relative to DIC concentration, it is preferable to modify the conventional isotopic concentration units (representing ${ }^{13} \mathrm{C} /{ }^{12} \mathrm{C}$ and ${ }^{14} \mathrm{C} /{ }^{12} \mathrm{C}$ ) to those which strictly represent ${ }^{13} \mathrm{C} / \mathrm{DIC}$ and ${ }^{14} \mathrm{C} / \mathrm{DIC}$. ${ }^{13} \mathrm{C}$ (Craig 1957) becomes $\delta^{\prime 13} \mathrm{C}$, which is now defined as the per mil difference between ${ }^{13} \mathrm{C} /\left({ }^{12} \mathrm{C}+{ }^{13} \mathrm{C}\right)$ of the sample and that of Vienna PDB standard (Coplen 1994); pMC (percent modern carbon) is altered to $\% \mathrm{MC}$, representing ${ }^{14} \mathrm{C} /\left({ }^{12} \mathrm{C}+{ }^{13} \mathrm{C}\right)$ of the sample as a percentage of the same ratio in $95 \%$ oxalic acid standard (Stuiver and Polach 1977). (For the sake of brevity, the per mil and percent symbols 
will be omitted throughout the text of this paper when used with these units of measurement). DIC concentrations are mmol kg-1 water. Total ${ }^{14} \mathrm{C}$ concentrations per unit mass of water can be conve-

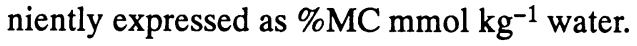

Process identification by ${ }^{13} \mathrm{C}$ or ${ }^{14} \mathrm{C}$ correlations relative to $1 / \mathrm{DIC}$ was previously proposed by Pearson and Swarzenki (1974), but the strategy is not often encountered in the later literature. One reason may be that the approach appears to work less satisfactorily when DIC concentrations measured by conventional chemical techniques are applied. This anomaly was already apparent as the New Zealand program was in the planning stage, and was the reason behind our underpinning technical step, which measures DIC with high precision (standard error $0.013-0.014 \mathrm{mmol} \mathrm{kg}^{-1}$ ) on the isotope sample. This accuracy is very easily attained by gravimetric determination of water sample quantity and DIC recovered quantitatively as $\mathrm{CO}_{2}$ for ${ }^{13} \mathrm{C}$ and ${ }^{14} \mathrm{C}$ measurement. This conceptually and technically simple step has proved to be the key to demonstrating the chemical evolution of DIC in closed situations with effectiveness and accuracy well beyond initial expectations.

Our usual field procedure is to precipitate DIC as strontium carbonate by adding $\mathrm{pH}$-adjusted strontium chloride solution to about 1 liter of sample water. In the laboratory, acidification by phosphoric acid under vacuum releases DIC as $\mathrm{CO}_{2}$, which can be frozen down into a small steel pressure bottle and weighed.

Examples of carbon isotope correlations in closed situations are depicted in Figures 1 and 2. Figure 1 shows $\delta^{13} \mathrm{C} v s$. 1/DIC for two confined New Zealand aquifers (Pohangina aquifer, Manawatu, SW North Island, New Zealand (Taylor et al. 1997); Matemateaonga aquifer, Taranaki, W North Island (study in progress)). The areal extent and separate identity of the Pohangina aquifer were identified and confirmed by combining evidence of chemical composition, $\delta^{18} \mathrm{O}$, potentiometric patterns and this carbon isotope correlation, which has resulted from the dissolution of calcite $\left(\delta^{\prime 13} \mathrm{C}=0\right)$ from a precursor isotopic composition at the bottom end of the correlation line. This ${ }^{13} \mathrm{C}$ correlation is not matched by an equivalent linear relationship of \%MC versus $1 / \mathrm{DIC}$. For some of the Pohangina samples, this mismatch is partially due to radioactive decay, but contributions of DIC from decaying organic material of variable age during an early stage of the closed path appear to have caused a range of \% MC concentrations prior to calcite dissolution (Taylor et al. 1997). The Matemateaonga Formation is a sandstone/mudstone-dominated sequence, and the calcite dissolution is likely to occur during flow through conglomeratic shellbeds near the top of the sloping aquifer. Interpretation of the ${ }^{14} \mathrm{C}$ data in this study area awaits further investigation.

In both cases shown in Figure 1, the increase of DIC concentration comes entirely from calcite, but is greater than can be attributed to initial acidity due to dissolved $\mathrm{CO}_{2}$; this isotopic trend is quite common in New Zealand aquifers and is due to dissolution by humic acids. The reaction produces $\mathrm{Ca}^{2+}$ and DIC in a 1:1 molar ratio, distinct from the usual weathering reactions for which the molar ratio is $1: 2$.

Figure 2 shows an equivalent \%MC vs. 1/DIC correlation in a confined aquifer within a sequence underlying the Poverty Bay flats (east coast North Island). The aquifer materials and confining silt layers contain finely divided calcite. Recharge to this aquifer is by precipitation on hills and valleys to the west of the flats. The groundwater exhibited traces of ${ }^{3} \mathrm{H}$ (less than TR $=0.1$, but above our present detection limit in the range TR $=0.03-0.04){ }^{1}$, and has thus not lost significant ${ }^{14} \mathrm{C}$ by radioactive decay. The extension of the ${ }^{14} \mathrm{C}$ dilution line toward the origin of the diagram is typical of cal-

${ }^{1} \mathrm{TR}=1 \mathrm{TU}$ (tritium unit) $\approx 3.2 \mathrm{pCi} \mathrm{L}-1$. 


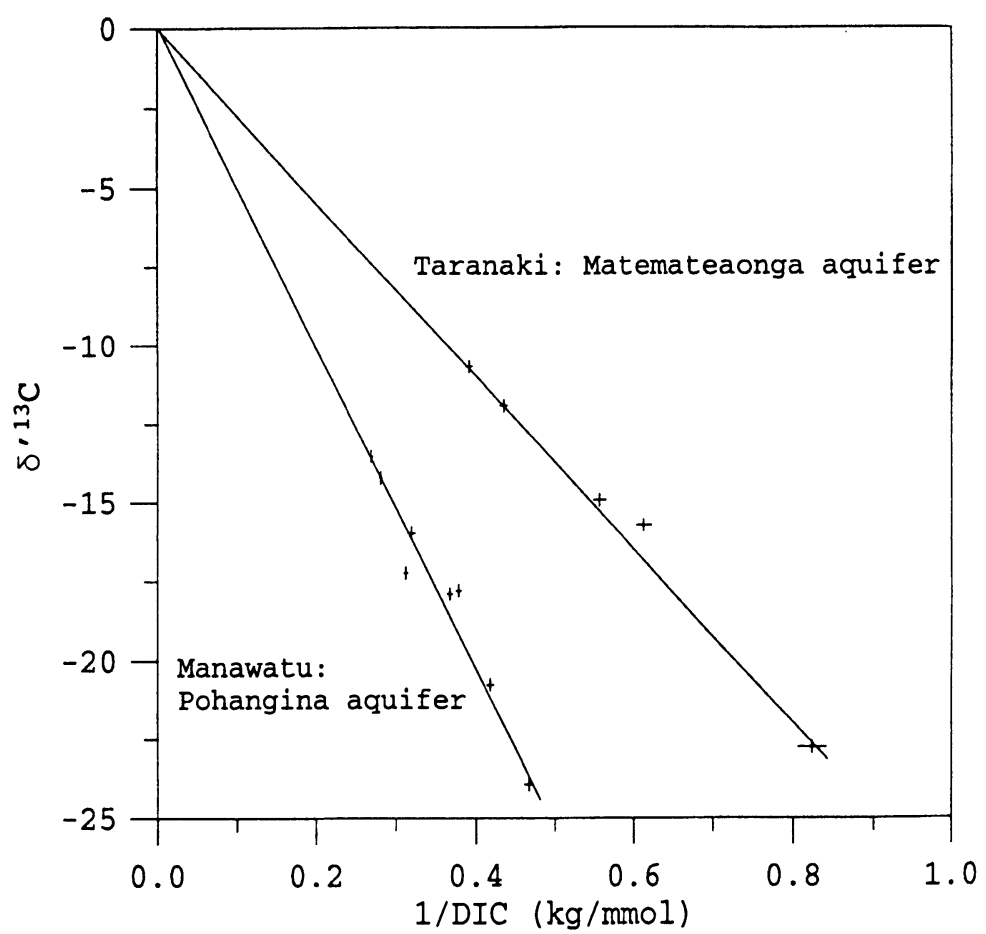

Fig. 1. Examples of $\delta^{\prime 13} \mathrm{C} v s$. 1/DIC correlations for confined, precipitation-recharged aquifers (Manawatu and Taranaki, New Zealand). Groundwater in both aquifers shows varying degrees of calcite dissolution from a precursor position near the bottom of the diagram.

cite dissolution by humic acid, not unexpected in the young marine-estuarine confining sediments. This interpretation is supported by the chemical evolution (Taylor 1994). The DIC concentrations are not limited by calcite saturation, as a consequence of $\mathrm{Ca}^{2+} / 2 \mathrm{Na}^{+}$exchange with the aquifer materials. Without the evidence provided by the ${ }^{3} \mathrm{H}$ concentrations and supporting chemical compositions, Figure 2 might have been incorrectly interpreted as a simple case of radioactive decay along a flow path. However, despite the excellent \%MC versus $1 / \mathrm{DIC}$ correlation, the $\left(\delta^{\prime 13} \mathrm{C}\right.$, DIC) compositions and a small range of $\delta^{18} \mathrm{O}$ revealed variable precursor conditions over the recharge area.

While such carbon isotope information is essential to identification of evolutionary processes of dissolved carbon and determination of aquifer residence times, it is equally valuable, when applied together with other chemical and isotopic tracers, in the overall assessment of the hydrogeology of regional aquifer systems. The Poverty Bay aquifer system is tectonically very young, and structurally highly complex. In this case, the identification of isotope correlations presently offers the best available tool for clarification of the overall aquifer structures, their recharge sources, flow paths and intermixing.

\section{ISOTOPIC COMPOSITIONS IN OPEN SITUATIONS}

Figures 1 and 2 demonstrate closed system evolution extending from regions of the isotope diagrams occupied by precursor (i.e., open system) waters. Data from New Zealand and other studies show that precursor positions are widely distributed within the range of isotopic and DIC concentrations 


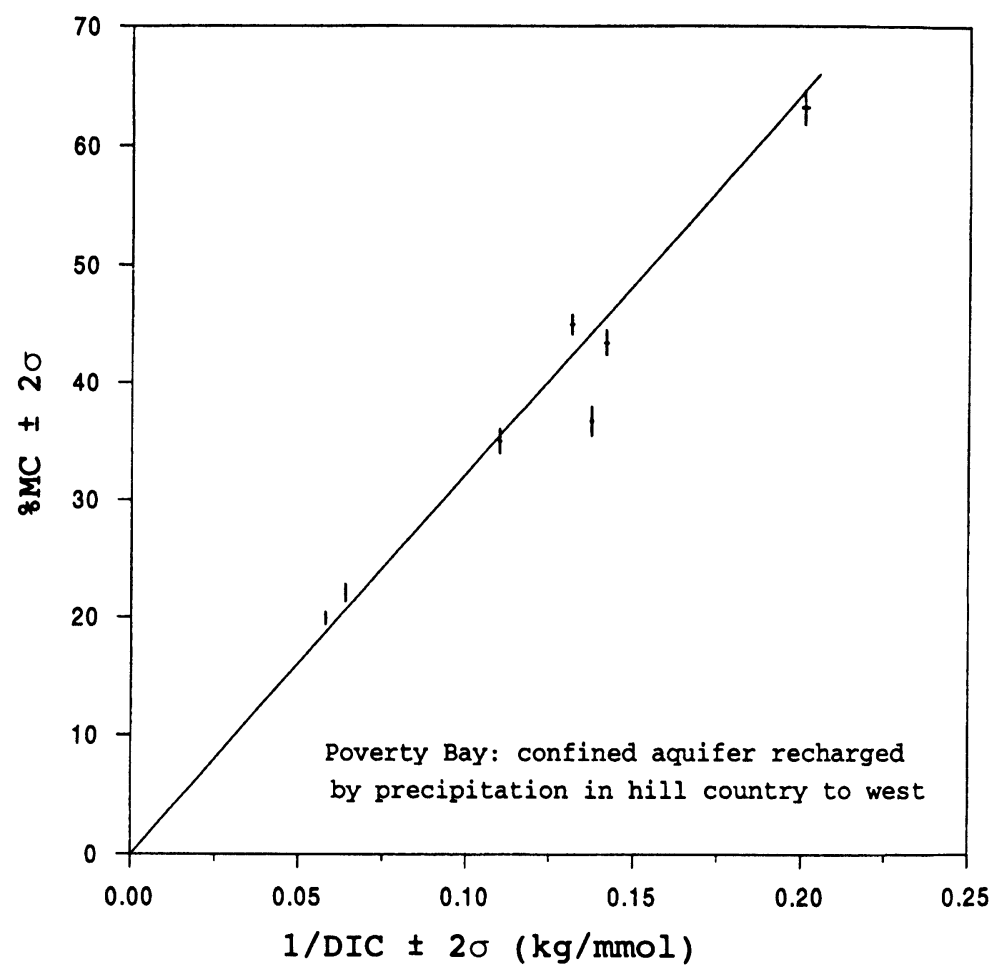

Fig. 2. An example of a \%MC vs. 1/DIC correlation in a confined, precipitation-recharged aquifer (Poverty Bay, New Zealand). The strong decrease of \%MC and increase of DIC concentration is due to dissolution of finely divided calcite in the aquifer materials by humic acid acquired from marine-estuarine confining layers. These waters had very low, but still detectable ${ }^{3} \mathrm{H}(\mathrm{TR}<0.1)$ and are thus of quite recent origin, despite the low \%MC values.

defined by these diagrams. It is therefore very desirable to reach a broad understanding of circumstances leading to particular isotopic compositions in the open situation.

Assessment of earlier models is not within the compass of this paper. Several of these were summarized and compared by Fontes and Garnier (1979) in a paper introducing a model of their own. The variability between the outcomes of different models appears to be due mainly to widely differing conceptions regarding the processes that control the isotopic composition of DIC in open situations. In the present paper, DIC in the open system will be modeled as a simple balance of inputs and outputs that causes the broad range of precursor ${ }^{14} \mathrm{C}$ concentrations reported in the literature. The patterns predicted and observed for ${ }^{13} \mathrm{C}$ are important to confirmation of the proposed concepts, and serve as a guide to clearer understanding of open system conditions.

The central concept of this model is that the steady-state isotopic concentrations of DIC in the open situation are controlled only by the balance between exchange of $\mathrm{CO}_{2}$ across the water/air interface and direct addition of $\mathrm{CO}_{2}$ to the water by plant respiration, decay of organic material, or any flux of $\mathrm{CO}_{2}$ from deeper levels. Processes such as calcite dissolution may augment DIC concentration during the approach to steady state, but are not involved in establishing the steady-state isotope concentrations. This was recognized by Cheng (1992) in developing an open system dissolution model, but his formulation has not incorporated the crucial direct addition component. Its inclusion is missing from the earlier models, and demonstration here of its controlling influence must cast consider- 
able doubt on their validity as conceptual and quantitative representations of the open system and precursor ${ }^{14} \mathrm{C}$ concentrations of DIC.

\section{DETAILS OF THE OPEN SYSTEM MODEL}

Many details of the model and procedures are in Taylor and Fox (1996). For the present paper, the approach has been tightened considerably by more rigorous attention to isotopic fractionation factors, together with incorporation of temperature dependence (range $0-30^{\circ} \mathrm{C}$ ), chemical equilibrium constants from Drever (1997) and isotopic fractionation factors from Mook (1980). Activity coefficients differing from unity can also be applied, though their role in the steady-state outcomes has been found to be rather insignificant. The model may be considered to be applicable in the $\mathrm{pH}$ range where $\mathrm{CO}_{3}{ }^{2-}$ is negligible relative to the other DIC components, i.e., in the range below $\mathrm{pH}=8.5$.

Table 1 summarizes parameters of the model for the typical present-day New Zealand situation. Whereas the isotopic concentrations are usually well defined for rivers, an age-depleted ${ }^{14} \mathrm{C}$ component is quite likely to be at least part of the directly added DIC in the shallow groundwater case.

TABLE 1. Parameters of Open System Model

\begin{tabular}{|c|c|}
\hline Parameter & Range / unit / comment \\
\hline Temperature & $0-30^{\circ} \mathrm{C}$ \\
\hline Atmospheric $\mathrm{CO}_{2}$ pressure & Any historical value (atm.) \\
\hline Soil $\mathrm{CO}_{2}$ pressure & Chosen multiples of atmospheric $\mathrm{CO}_{2}$ pressure \\
\hline DIC concentration & Appropriate range $\left(\mathrm{mmol} \mathrm{kg}^{-1}\right)$ \\
\hline $\begin{array}{l}\text { Activity and fugacity coefficients for } \\
\mathrm{HCO}_{3}^{-}, \mathrm{CO}_{2} \text { (aq.), atmospheric } \mathrm{CO}_{2}\end{array}$ & Selectable \\
\hline $\begin{array}{l}\text { Relevant chemical equilibrium } \\
\text { constants }\end{array}$ & Temperature-dependent from Drever (1997) \\
\hline$\delta^{\prime 13} \mathrm{C}$ of atmospheric $\mathrm{CO}_{2}$ & Any chosen recent or historical value \\
\hline$\delta^{\prime 13} \mathrm{C}$ of soil $\mathrm{CO}_{2}$ & Selectable, based on vegetation type \\
\hline$\delta^{\prime 13} \mathrm{C}$ of directly added $\mathrm{CO}_{2}$ & Similar to that of soil $\mathrm{CO}_{2}$ \\
\hline${ }^{13} \mathrm{C}$ isotopic fractionation & Temperature-dependent, from Mook (1980) \\
\hline${ }^{14} \mathrm{C}$ isotopic fractionation & Deviations from unity double those of ${ }^{13} \mathrm{C}$ \\
\hline Rate of $\mathrm{CO}_{2}$ direct addition & $\begin{array}{l}\left.\text { Ratio of addition rate (mmol kg-1 } \mathrm{s}^{-1}\right) \text { to the forward rate } \\
\text { constant }\left(\mathrm{s}^{-1}\right) \text { of reaction } \mathrm{CO}_{2}(\mathrm{aq} .) \Leftrightarrow \mathrm{CO}_{2}(\text { atm. }) \text {. Rivers } \\
\text { ca. } 0-0.1 \mathrm{mmol} \mathrm{kg}{ }^{-1} \text {. Groundwater } c a .0 .1-1.0 \mathrm{mmol} \\
\mathrm{kg}^{-1}\end{array}$ \\
\hline $\begin{array}{l}\text { Fractionation in forward step of } \\
\mathrm{CO}_{2} \text { (aq.) } \Leftrightarrow \mathrm{CO}_{2} \text { (atm.) }\end{array}$ & 1.0005 for ${ }^{13} \mathrm{C}, 1.001$ for ${ }^{14} \mathrm{C}$ \\
\hline
\end{tabular}

The parameter values of Table 1 apply to present-day conditions, but of course many have varied considerably over the ${ }^{14} \mathrm{C}$ time scale. This requires that the model is able to accommodate the parameter ranges that may have applied to precursors of old groundwater. With this in mind, any input variable or parameter can be altered or reformulated to obtain immediate output updates. 
The most significant model parameter is the ratio ( $\mathrm{mmol} \mathrm{kg}^{-1}$ water) of the direct $\mathrm{CO}_{2}$ addition rate $\mathrm{k}\left(\mathrm{mmol} \mathrm{kg}^{-1}\right.$ water s $\left.\mathrm{s}^{-1}\right)$ to that of the forward rate constant $\mathrm{k}_{+}\left(\mathrm{s}^{-1}\right)$ of the exchange reaction

$$
\mathrm{CO}_{2} \text { (dissolved) } \Leftrightarrow \mathrm{CO}_{2} \text { (gas phase). }
$$

The model calculations can proceed in two alternative ways. One spreadsheet allows progress toward equilibrium of the parameters $\mathrm{pH}, \mathrm{DIC}$, dissolved $\mathrm{CO}_{2}, \delta^{\prime 13} \mathrm{C}$ and $\% \mathrm{MC}$ to be tracked toward steady state, from any arbitrarily chosen (but necessarily realistic) initial state. In the assumed absence of any other DIC-contributing processes, the dissolved $\mathrm{CO}_{2}$ component $\mathrm{m}$ of DIC (mmol $\mathrm{kg}^{-1}$ water) approaches its equilibrium value as an exponential function of time, whose time constant is the exchange rate $\mathrm{k}_{+}$of $\mathrm{CO}_{2}$ across the interface in the direction water-air.

$$
\mathrm{m}-\mathrm{k} / \mathrm{k}_{+}-\mathrm{KP}=\left(\mathrm{m}_{0}-\mathrm{k} / \mathrm{k}_{+}-\mathrm{KP}\right) \exp \left(-\mathrm{k}_{+} \mathrm{t}\right)
$$

where $m_{0}$ is the initial concentration, $K$ is the chemical equilibrium constant of the exchange reaction (expressed here as mmol atm ${ }^{-1}$ ), and $\mathrm{P}$ is the partial pressure (atm) of $\mathrm{CO}_{2}$ in the gas phase. (A typographical error of sign appeared in the equivalent equation in Taylor and Fox 1996). In using Equation 1, the model makes the reasonable assumption (Münnich and Siegenthaler 1981) that rate and equilibrium constants applied to $\mathrm{m}={ }^{12} \mathrm{C}+{ }^{13} \mathrm{C}$ are effectively independent of variations of ${ }^{13} \mathrm{C}$ concentration.

This approach to the overall chemical balance of the open system assumes that the water reservoir is well mixed, and that the dissolved $\mathrm{CO}_{2} \Leftrightarrow$ bicarbonate equilibrium is not rate-controlling. Constraints of charge balance and chemical equilibrium prevent appreciable change of bicarbonate concentration as a result of the water-air exchange process. The well-mixed criterion is obviously satisfied more closely by rivers. For groundwater, concentration gradients occur in a thin layer at the phase boundary, which offers the main resistance to the exchange of $\mathrm{CO}_{2}$. The DIC content in this boundary layer is so small that it can be ignored as a significant component of DIC in the overall chemical and isotopic balance of the open reservoir, although it determines the extent of the isotopic fractionation.

As an example of the application of Equation 1, Figure 3 shows the approach of $\mathrm{pH}$ and DIC toward equilibrium for two situations involving a small rate of direct biogenic $\mathrm{CO}_{2}$ input. One case applies to shallow groundwater where soil $\mathrm{CO}_{2}$ pressure is 10 times greater than that of atmospheric $\mathrm{CO}_{2}$, while the other applies to rivers. Other examples of the approach to DIC equilibrium were presented in Taylor and Fox (1996).

For ${ }^{13} \mathrm{C}$ or ${ }^{14} \mathrm{C}$, the equivalent equation to (1) can be expressed as

$$
\mathrm{rm}-\mathrm{r}_{\mathrm{g}} \mathrm{K}^{\prime} \mathrm{P}+\mathrm{r}_{\mathrm{b}} \mathrm{k} / \mathrm{k}_{+}{ }^{\prime}=\left(\mathrm{r}_{0} \mathrm{~m}_{0}-\mathrm{r}_{\mathrm{g}} \mathrm{K}^{\prime} \mathrm{P}+\mathrm{kr}_{\mathrm{b}} / \mathrm{k}_{+}{ }^{\prime}\right) \exp \left(-\mathrm{k}_{+}{ }^{\prime} \mathrm{t}\right)
$$

where $r, r_{0}, r_{g}, r_{b}$ represent respectively the isotopic ratios (with respect to ${ }^{12} \mathrm{C}+{ }^{13} \mathrm{C}$ ) of dissolved $\mathrm{CO}_{2}$, initial dissolved $\mathrm{CO}_{2}$, gas phase $\mathrm{CO}_{2}$ and direct biogenic $\mathrm{CO}_{2}$ input, but expressed here as fractions relative to the isotopic ratios of the international standards. Equilibrium and rate constants for the heavy isotopes are assigned dashed symbols.

A second spreadsheet enables the loci of steady states and their dependence on parameter variation to be studied. The isotopic ratios $r_{e}$ (DIC) of DIC at steady-state concentration $m_{e}(D I C)$ can be represented by the formula

$$
r_{e}(D I C)=m_{e} m(D I C)_{e}{ }^{-1} r_{e}(1-\alpha)+\alpha r_{e}
$$




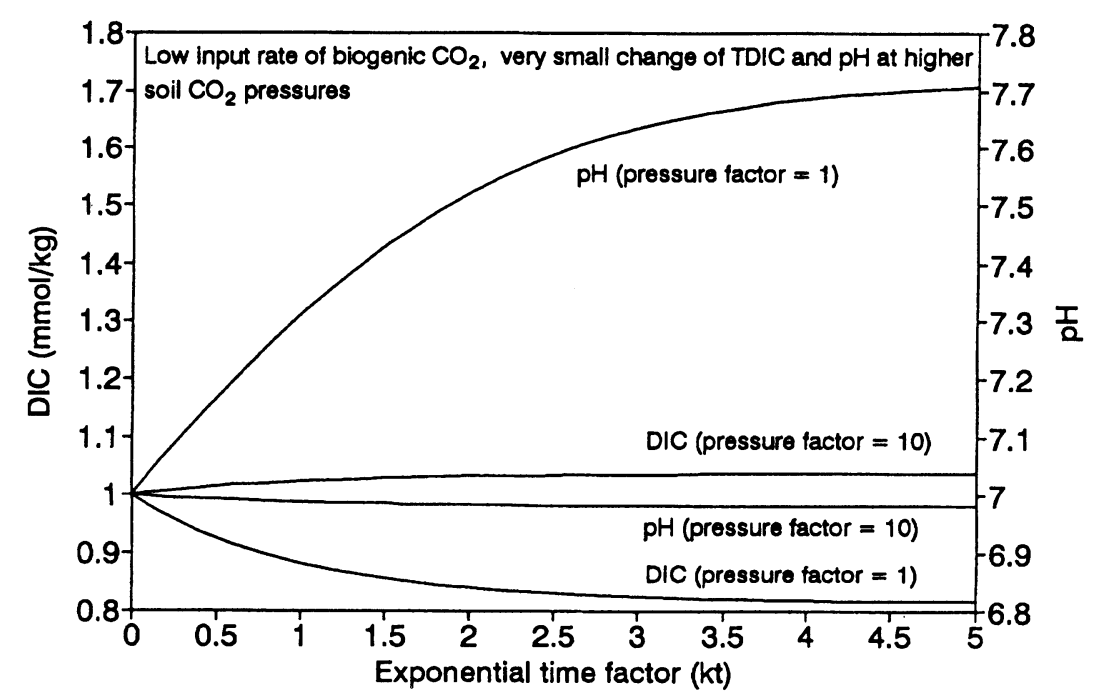

Fig. 3. Exponential approach of $\mathrm{pH}$ and DIC towards steady state for a river (pressure factor $=1$ ) and open system groundwater (pressure factor $=10$ ) for starting conditions $\mathrm{pH}=7$ and DIC concentration $=1 \mathrm{mmol} \mathrm{kg}^{-1}$, and a small rate of direct DIC addition $\left(\mathrm{k} / \mathrm{k}_{+}=2.5 \times 10^{-5} \mathrm{mmol} \mathrm{kg}^{-1}\right)$

$\alpha$ (greater than 1) is the temperature-dependent isotopic fractionation factor between dissolved $\mathrm{CO}_{2}$ and bicarbonate. The steady-state values $m_{e}$ and $r_{e}$ are the solutions of Equations 1 and 2 for $t=\infty$. Equation 3 demonstrates that the locus of equilibrium isotopic ratios at steady state is a linear function of the reciprocal of DIC concentration, whose negative gradient steepens with increase of both soil $\mathrm{CO}_{2}$ pressure and the direct addition rate constant $\mathrm{k}$.

For any chosen set of parameters, $m_{e}$ (DIC) cannot be less than the equilibrium value of $m_{e}$. This condition is applied in the calculations to prevent the appearance of nonrealistic steady states. The upper bound of DIC is not strictly set, because exchange reactions $\mathrm{Ca}^{2+} / 2 \mathrm{Na}^{+}$with aquifer materials may allow high DIC concentrations without exceeding calcium carbonate solubility. However, the upper bound obviously has to be judged for the hydrochemical conditions applying in individual situations.

A significant conclusion from this line of argument is that the occurrence of other chemical processes during the approach to steady state cannot have any effect other than to move the steady state isotopic composition to another position up or down the line defined by Equation 3. For example, lowering of $\mathrm{pH}$ can encourage calcite dissolution. At steady state, this reaction will have ceased, but the isotopic ratio will occupy a position on the line reflecting the increased DIC concentration.

Steady-state Equation 3 becomes the basis by which measured isotopic compositions of DIC at the conclusion of the open system stage can be assessed. Another significant aspect of Equation 3 is the prediction that the total ${ }^{14} \mathrm{C}$ concentration per unit mass of water, proportional to $r_{e}(D I C) m_{e}(D I C)$, is a linear function of $m_{e}(D I C)$. This provides a third, very useful isotope diagram.

Although steady-state compositions for rivers and shallow groundwater can be determined for fixed parameter values, it should be understood that the equilibrium is always dynamic in nature, responding to parameter variations in respect of both time and location. Rivers are affected by tributary and groundwater inflow, seasonal and diurnal temperature variation, and changes in the content of 
decaying organic material. The most significant parameter variations for groundwater are likely to be the seasonal changes in plant respiration and soil $\mathrm{CO}_{2}$ pressure.

Expansion of Equation 3, using Equations 1 and 2, reveals that steady-state isotopic compositions depend on the ratios $\mathrm{K} / \mathrm{K}^{\prime}$ and $\mathrm{k}_{+} / \mathrm{k}_{+}{ }^{\prime}$. The first of these is the equilibrium fractionation between dissolved $\mathrm{CO}_{2}$ and that in the gas phase, for which the model uses the temperature-dependent formula given by Mook (1980); the gas phase enrichment for ${ }^{13} \mathrm{C}$ is $\mathrm{ca} .1 \%$. The ratio $\mathrm{k}_{+} / \mathrm{k}_{+}{ }^{\prime}$ is the fractionation in the forward step of the exchange reaction, i.e., that which would occur if dissolved $\mathrm{CO}_{2}$ were escaping into a $\mathrm{CO}_{2}$-free atmosphere. This could be determined by direct measurement in the laboratory, or from the equilibrium fractionation and that prevailing in the opposite direction. Reasoning from the relationship of transfer velocities to diffusion coefficients in the ocean boundary layer, Siegenthaler and Münnich (1981) predicted a ${ }^{13} \mathrm{C}$ fractionation corresponding to $\mathbf{k}_{+} / \mathbf{k}_{+}{ }^{\prime}=$ 1.0005 for ocean water. For such a small fractionation effect, uncertainty on the order of 0.0001 produces no significant change to the model steady-state predictions, and possible temperature dependence can be ignored. The ratio 1.0005 has been applied for all the river and groundwater examples shown here, but other values can be selected if desired.

Fractionation factors for ${ }^{14} \mathrm{C}$ have been assumed to deviate from unity by double the deviation $(\varepsilon$ value) applied for ${ }^{13} \mathrm{C}$.

\section{EXAMPLES OF PREDICTIONS AND DATA FOR RIVERS}

Figure 4 shows model predictions for rivers. These are steady-state solutions of $\delta^{\prime 13} \mathrm{C} v s .1 / \mathrm{DIC}$ for a range of ratios $\mathrm{k} / \mathrm{k}_{+}(\mathrm{mmol} / \mathrm{kg})$, demonstrating the extent of responses if temperature changes from $10^{\circ} \mathrm{C}$ to $15^{\circ} \mathrm{C}$. Figure 5 shows the steady states for $10^{\circ} \mathrm{C}$ together with some data for New Zealand rivers. The Waimakariri River (North Canterbury) drains a large hill/mountain catchment complex between the Canterbury Plains and the Alpine divide (Taylor et al. 1989; Taylor and Fox 1996). The catchments contain only minor areas of limestone rock, and the river has very low DIC concentra-

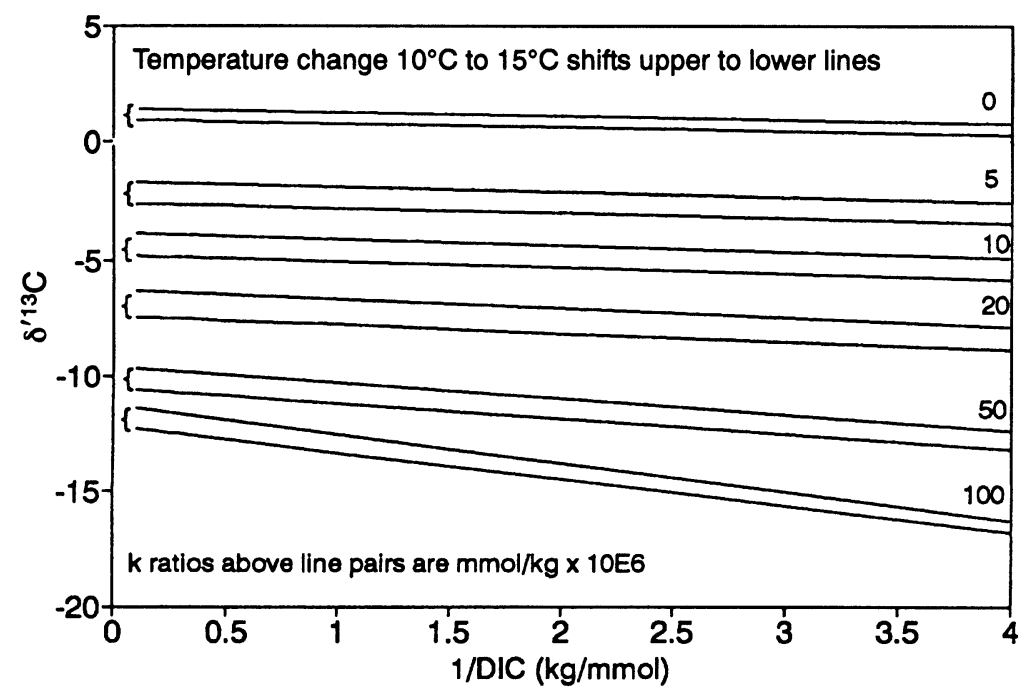

Fig. 4. Model-predicted steady states $\left(\delta^{\prime 13} \mathrm{C} v\right.$ s. $\left.1 / \mathrm{DIC}\right)$ for present-day rivers for various direct biogenic $\mathrm{CO}_{2}$ inputs (represented by $\mathrm{k} / \mathrm{k}_{+}$ratios), illustrating the effect of temperature change $\left(10-15^{\circ} \mathrm{C}\right)$ 


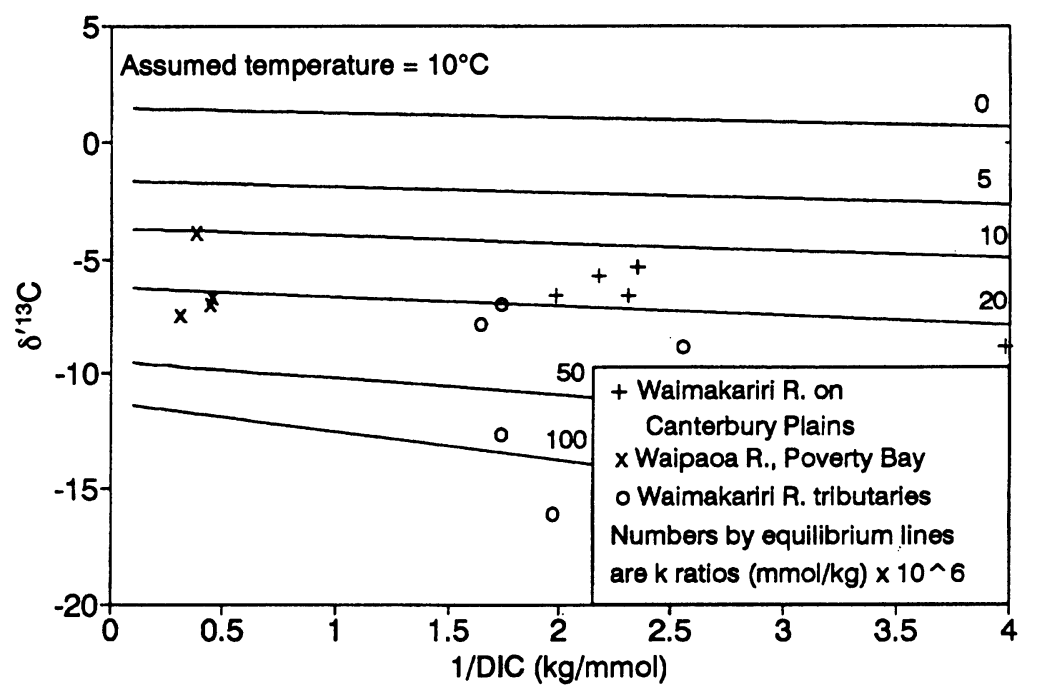

Fig. 5. Steady-state predictions for present-day rivers with various direct biogenic DIC inputs (represented by $\mathrm{k} / \mathrm{k}_{+}$ratios) at temperature $10^{\circ} \mathrm{C}$, coupled with data for two New Zealand rivers (Waimakariri and Waipaoa, also Waimakariri tributaries)

tion. Samples shown in Figure 5 were collected at the location on the North Canterbury Plains where the river recharges the deep Plains aquifer system. The position of the data points relative to the model steady-state lines demonstrates the influence of a small, directly added biogenic component; the sample at the extreme right of the diagram was collected when the river was in flood. The three tributary points with $\delta^{\prime 13} \mathrm{C}$ close to the values on the Plains are for the river and two major tributaries above the Waimakariri Gorge $>50 \mathrm{~km}$ above the Plains sampling location. The two more negative $\delta^{\prime 13} \mathrm{C}$ values are for the Kowai River, the only significant tributary below the Gorge; their position on the diagram could suggest significantly enhanced biogenic input relative to the other samples from this river system, or alternatively non-attainment of steady state for a shorter tributary whose input water has more negative $\delta^{\prime 13} \mathrm{C}$ values (Taylor and Fox 1996).

The Waipaoa River is the major river flowing across the Poverty Bay flats. Its $\delta^{\prime 13} \mathrm{C}$ values (Fig. 5) suggest similar biogenic input to that of Waimakariri river, but greater DIC concentrations reflect the presence of finely divided calcite $(c a .1 \%)$ in the extremely high sediment load of this river.

Figures 4 and 5 offer a framework within which ${ }^{13} \mathrm{C}$ data for rivers can be assessed. If rivers recharge groundwater, these precursor compositions may be subject to rapid readjustment by addition of $\mathrm{CO}_{2}$ through decay of organic material carried with the water or trapped in the flow path of the recharge. Figure 6 shows examples of such adjustment for the case of the Waimakariri River. One adjustment is between the river sampled during a period of relatively low flow (December 1993) at the recharge stretch and a down-gradient well of depth $50 \mathrm{~m}$ situated $c a .1 \mathrm{~km}$ away. The displacements of $\delta^{\prime 13} \mathrm{C}$ and \% $\mathrm{MC}$ indicate addition of biogenic DIC of recent origin (\% $\mathrm{MC}>100)$ under closed conditions. In contrast, the isotopic composition of a nearby shallow well (depth $8.2 \mathrm{~m}$ ) shows the influence of open system exchange with soil $\mathrm{CO}_{2}$ (more negative $\delta^{\prime 13} \mathrm{C}$, enhanced $\% \mathrm{MC}$ toward \%MC of atmospheric $\mathrm{CO}_{2}$ ).

A consequence of the range of $\mathrm{k} / \mathrm{k}_{+}$ratios demonstrated by the preceding examples is a prediction that total ${ }^{14} \mathrm{C}$ contents of rivers evaluated from Equation 3 should be a linear function of DIC concentration, with gradient close to \%MC of the atmosphere and negative intercept very close to zero. 


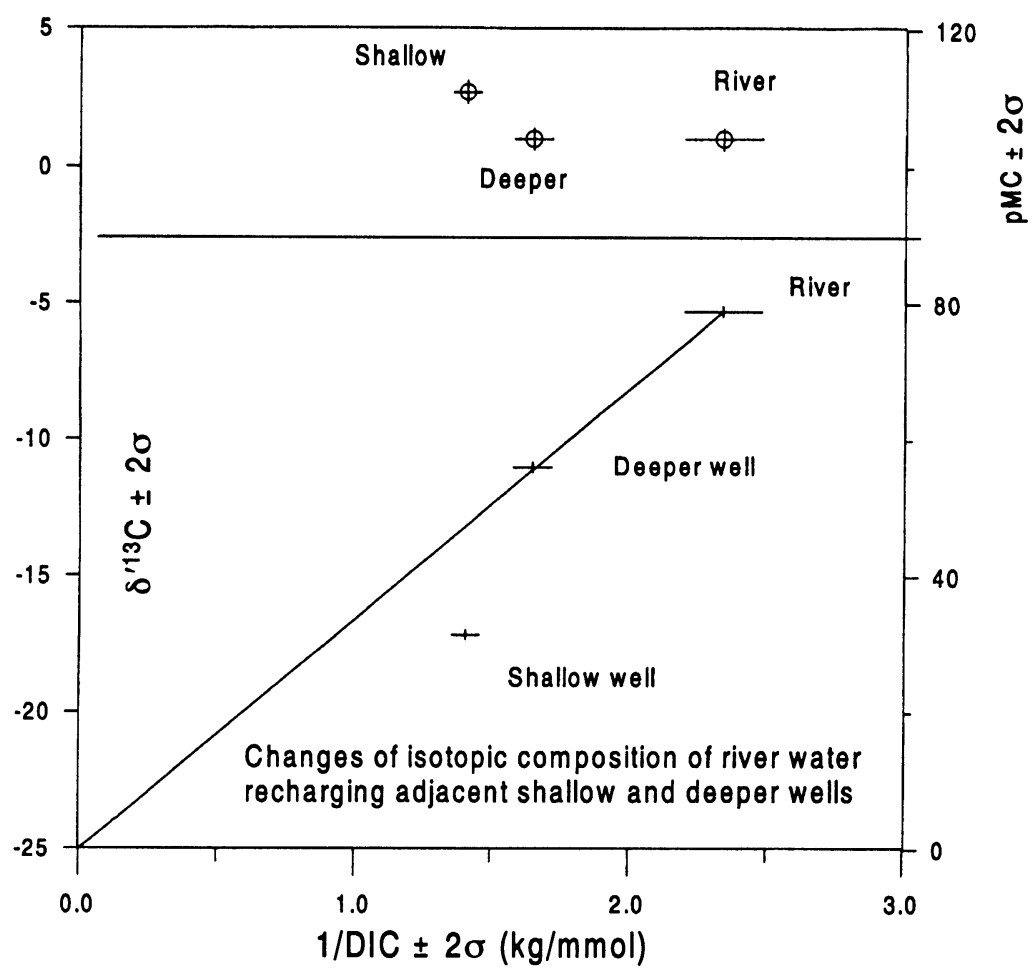

Fig. 6. Closed system accrual of DIC by decay of organic material subsequent to recharge from Waimakariri R. is revealed by plots of $\delta^{\prime 13} \mathrm{C} v s$. 1/DIC for the river and a nearby $50 \mathrm{~m}$ deep well, contrasting with the open system evolution of isotopic composition from the same precursor river water fed into a shallow situation (well depth $8.2 \mathrm{~m}$ ). \% MC does not increase appreciably in the closed case, but adjusts upwards toward atmospheric level in the shallow well.

Figure 7 shows this relationship for the Canterbury rivers, plotted together with closely spaced equilibrium lines encompassing a realistic range of $k / k_{+}$ratios and other indicated parameters.

\section{EXAMPLES OF MODEL PREDICTIONS AND DATA FOR SHALLOW GROUNDWATER}

The open system model framework for the case of modern rivers is simplified by accurate knowledge of pressure and isotopic composition of atmospheric $\mathrm{CO}_{2}$, and the good chance that all the ${ }^{14} \mathrm{C}$ components are modern. This advantage is not available for groundwater, where $\delta^{\prime 13} \mathrm{C}$ of soil atmospheric and biogenic $\mathrm{CO}_{2}$ may be the only parameters known with accuracy. The appreciable spatial and time variability of soil $\mathrm{CO}_{2}$ pressure cannot usually be practically assessed. The model must assume either fixed $\mathrm{CO}_{2}$ pressure (entered as a multiple of atmospheric $\mathrm{CO}_{2}$ pressure) and variable $\mathrm{k} / \mathrm{k}_{+}$ratios, or vice versa. For the second of these scenarios, Figure 8 contrasts steady-state lines and groundwater data with the previously shown river situation from Figure 5. The more negative $\delta^{\prime 13} \mathrm{C}$ of soil $\mathrm{CO}_{2}$ (assumed -24.7), higher $\mathrm{CO}_{2}$ pressure and greater biogenic input combine to cause higher DIC concentrations and more negative $\delta^{\prime 13} \mathrm{C}$ values for the groundwater, and to steepen the negative slopes of the steady-state lines. Shallow groundwater data points are from studies in the Manawatu (SW North Island) and Taranaki (W North Island), both aquifer systems being precipitation-recharged. Whereas the Taranaki data points, characteristic of an open situation, show no obvious trend with variation of DIC, the Manawatu samples are linearly correlated, suggesting closed 
system biogenic $\mathrm{CO}_{2}$ addition to shallow precursors of uniform composition typical of an open situation. This correlation is crucial information for interpretation of the variable \% MC values exhibited by shallow groundwater of the Manawatu (Taylor et al. 1997).

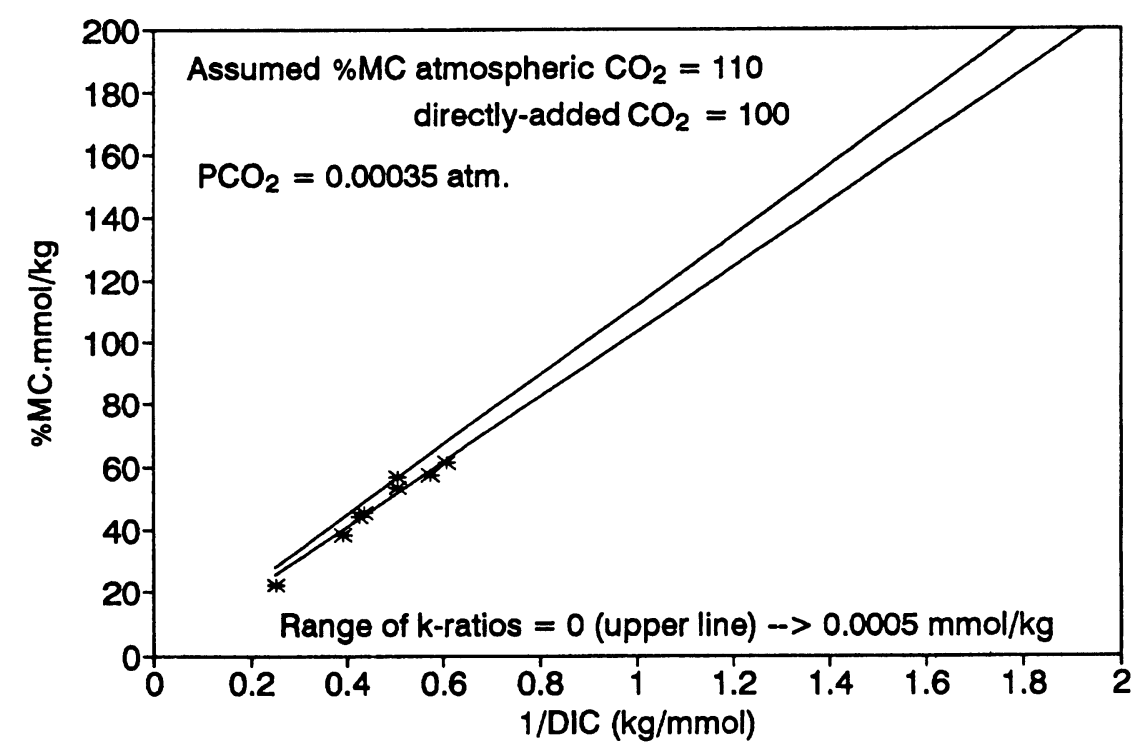

Fig. 7. Data for the total ${ }^{14} \mathrm{C}$ concentrations of Waimakariri $\mathrm{R}$. and tributary samples (\%MC mmol kg-1 water) $v$ s. DIC concentration match the predictions of the open system model (equilibrium lines) under the indicated conditions

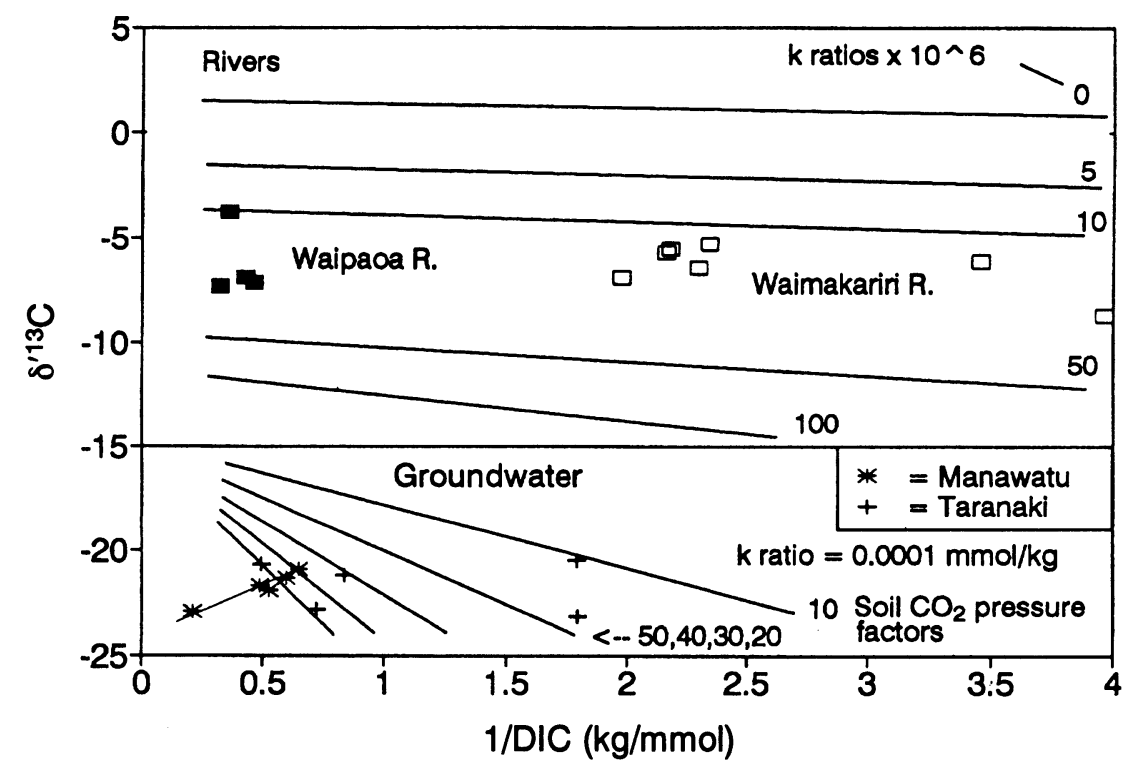

Fig. 8. This diagram contrasts the open system model predictions and data $\left({ }^{13} \mathrm{C}\right)$ for rivers (from Fig. 5 , temperature $10^{\circ} \mathrm{C}$ ) with those for shallow groundwaters of Manawatu and Taranaki $\left(14^{\circ} \mathrm{C}\right)$. Groundwaters exchange with soil $\mathrm{CO}_{2}\left(\delta^{\prime 13} \mathrm{C} \approx-24.7\right)$ at partial pressures normally well in excess of that of atmospheric $\mathrm{CO}_{2}$, and rates of biogenic addition are also much enhanced relative to rivers. Manawatu samples show evidence of closed system addition of biogenic DIC. 
Figure 9 shows again the shallow groundwater data and steady-state lines of Figure 8, for comparison with Figure 10, in which the data is plotted on identical axes, but with steady-state lines for the case of variable $\mathbf{k} / \mathbf{k}_{+}$ratio and constant soil $\mathrm{CO}_{2}$ pressure. The comparison shows that greater $\mathbf{k} / \mathbf{k}_{+}$ ratios and soil $\mathrm{CO}_{2}$ pressures shift steady states in similar fashion, i.e., toward the bottom left corner

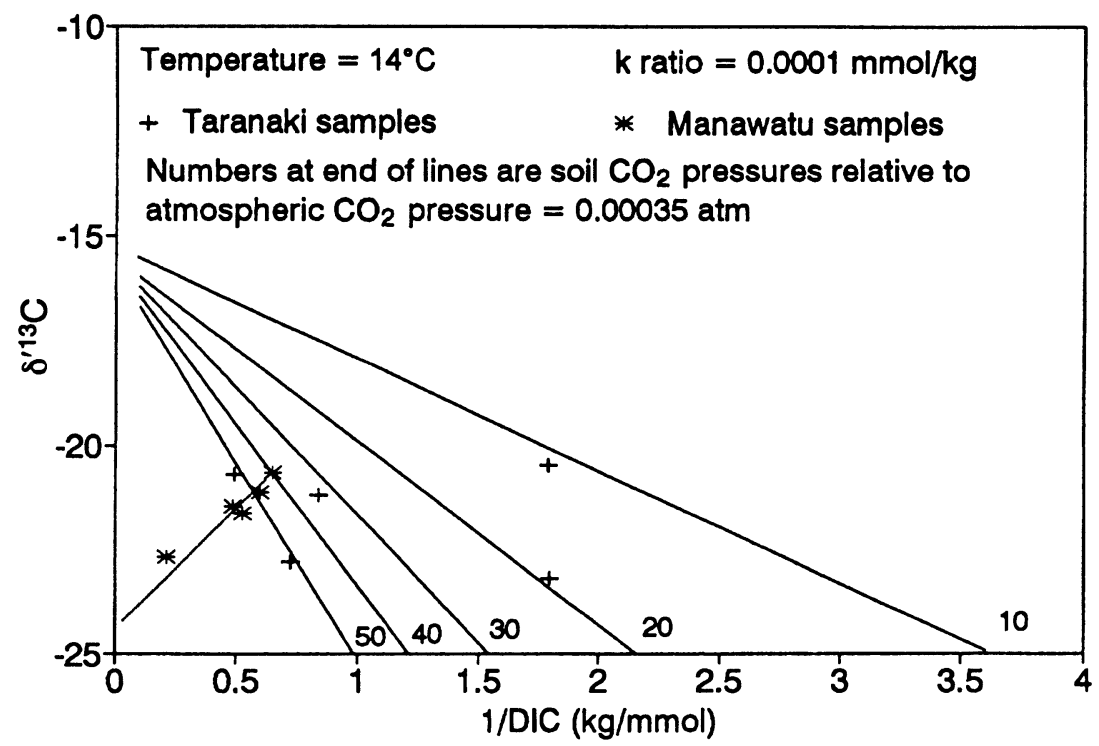

Fig. 9. The open system model predictions and groundwater data from Fig. 8 are replotted here for comparison with Fig. 10, to demonstrate that the model predicts similar outcomes for the case of variable soil $\mathrm{CO}_{2}$ pressure with constant biogenic $\mathrm{CO}_{2}$ input (this diagram) and for the reverse case (Fig. 10).

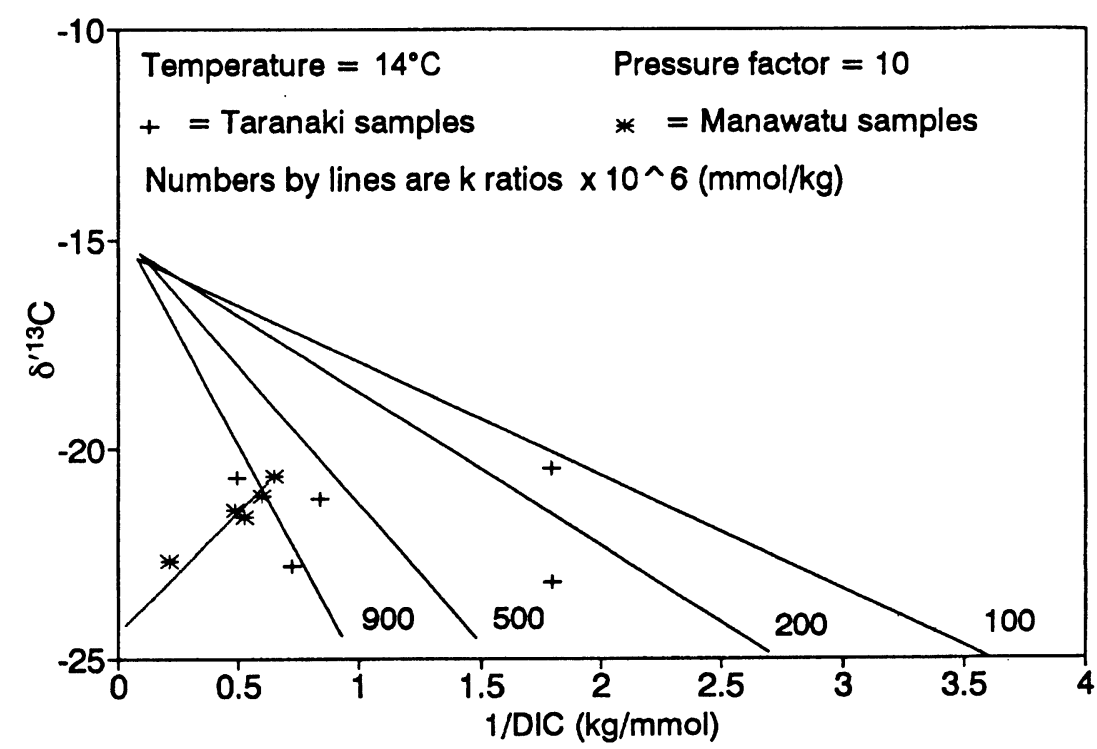

Fig. 10. Open system model predictions for variable biogenic input and constant soil $\mathrm{CO}_{2}$ pressures are similar to the reverse situation depicted in Fig. 9 (data from Manawatu and Taranaki). 
of the diagram, with lines of steeper negative slope. Higher $\mathrm{k} / \mathrm{k}_{+}$ratios are likely to coincide with high soil $\mathrm{CO}_{2}$ pressures, and therefore a sample point situated in that corner will typify such a situation. Similarly, less negative $\delta^{\prime 13} \mathrm{C}$ values and lower DIC concentrations at the right-hand end of the diagram reflect an open situation with lower biogenic influence.

A strong advantage of this model scenario is that it allows recognition of anomalous isotopic compositions. In a study area dominated by $\mathrm{C}_{3}$ vegetation, $\delta^{\prime 13} \mathrm{C}$ values less negative than -15 are clearly inconsistent with a steady-state open situation. Some likely causes of such exceptions would be 1) a non-steady state situation, e.g., river-recharged water not yet adjusted to a shallow groundwater steady state; 2 ) the shallow groundwater is already in a closed situation and has dissolved calcite; 3 ) the influence of enriched $\mathrm{CO}_{2}$ associated with microbial methanogenesis.

In a similar manner to the river data shown in Figure 7, shallow groundwaters whose balance components are entirely recent should exhibit a linear relationship between ${ }^{14} \mathrm{C}$ concentration per unit mass of water and DIC concentration, with gradient close to $\% \mathrm{MC}$ of atmospheric $\mathrm{CO}_{2}$ and negative intercept close to zero. Figure 11 combines data from three separate areas (Canterbury, Taranaki and Manawatu, collected during 1993-1997), for samples whose ${ }^{3} \mathrm{H}$ concentrations indicated recent origin (recent in this context means not subject to significant ${ }^{14} \mathrm{C}$ decay). The Canterbury and Taranaki data include both shallow groundwater and rivers. All the Canterbury and all but one of the Taranaki samples lie on the correlation line shown, with gradient $\% \mathrm{MC}=113$, which is a close match to the atmospheric \% MC value over this period.

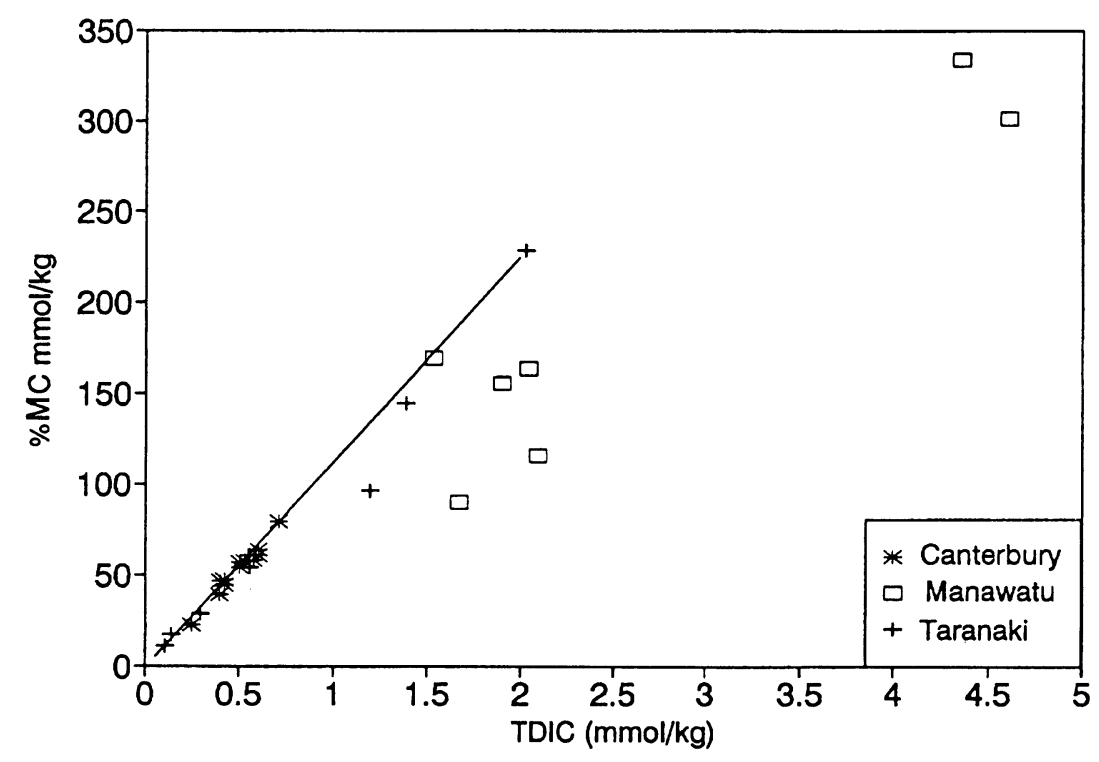

Fig. 11. Total ${ }^{14} \mathrm{C}$ concentrations ( $\% \mathrm{MC} \mathrm{mmol} \mathrm{kg}{ }^{-1}$ ) vs. DIC concentration for shallow groundwaters in Canterbury, Taranaki and Manawatu, coupled with river data from Canterbury and Taranaki. All the Canterbury and all but one of the Taranaki samples, but only one from the Manawatu set, lie on the same correlation line, which is clearly a benchmark isotopic indicator for open system waters whose DIC is influenced only by recent soil $\mathrm{CO}_{2}$ and biogenic addition. The departure from this line in the case of some of the Manawatu samples is due to the addition of "older" biogenic $\mathrm{CO}_{2}$ under closed conditions (see data in Figs. 8-10 and explanation in text). 
The strict adherence of so many experimental points to the relationship shown in Figure 11 confirms the wisdom of measuring DIC on the isotope sample. At the same time, it provides justification for giving serious consideration to the circumstances which have produced any outliers. Only one of the Manawatu shallow waters lies on the open system line. This is the sample at the top end of the Manawatu points in Figures 9 and 10 . This ${ }^{13} \mathrm{C}$ correlation suggested further accrual of DIC by decay of organic material. But the ${ }^{14} \mathrm{C}$ diagram (Fig. 11) reveals that the ${ }^{14} \mathrm{C}$ contents of the individual samples did not evolve from a single precursor position on the open system line. Bearing in mind that these were samples with detectable ${ }^{3} \mathrm{H}$ (a single exception is marked with a star), it is clear that they could not have evolved by radioactive decay of open system precursors with significantly higher initial total ${ }^{14} \mathrm{C}$ content. The Manawatu sample with the second lowest ${ }^{14} \mathrm{C}$ content is a mixed water due to upwards leakage from a deeper confined aquifer, while that with the highest total ${ }^{14} \mathrm{C}$ content had $\delta^{\prime 13} \mathrm{C}=3.6$, a positive value due to influence of $\mathrm{CO}_{2}$ associated with shallow-derived methane (Taylor et al. 1997). Each of the other four outliers derives by addition of biogenic DIC of unknown age to a precursor water on an open system line pertaining to the atmospheric \%MC value during their respective open system phases. For example, the sample at $(154,1.88)$ in Figure 11 is a pre-bomb water ( $T R=0.099 \pm 0.020)$, and would have derived from an open system line with slope slightly less than the line shown.

The correlation line for Poverty Bay samples (river and both river- and precipitation-derived groundwater) of recent age is shown separately as Figure 12, the DIC and total ${ }^{14} \mathrm{C}$ concentrations being much greater than those of the three aquifer systems shown in Figure 11. Many of these samples were already in confined aquifers. The outliers are due to horizontal displacement as the result of varying degrees of dissolution of finely divided calcite in the aquifer, in some cases aided by humic acid. Indeed, the samples farther up the line are almost certainly displaced a little in this manner, resulting in an apparently slightly lower gradient than would be expected for open system water at the times of recharge. Such a presentation of ${ }^{14} \mathrm{C}$ data, interpreted in conjunction with locations,

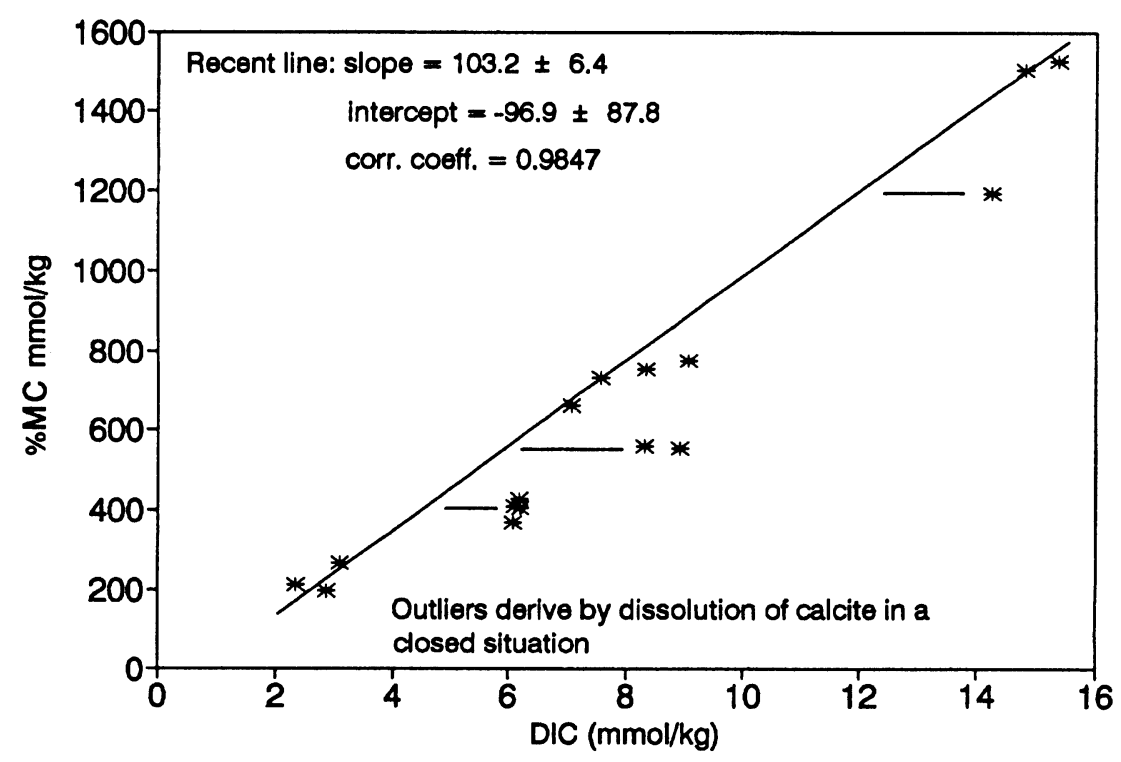

Fig. 12. Poverty Bay flats aquifer system: total ${ }^{14} \mathrm{C}$ Concentrations $\left(\% \mathrm{MC} \mathrm{mmol} \mathrm{kg}^{-1}\right)$ vs. DIC concentration, for rivers and groundwater samples (both river- and precipitation-recharged) with measurable ${ }^{3} \mathrm{H}$ (range pre-bomb to recent). 
depths and other isotope tracers, becomes an important aid to clarification of the chemical and structural features of such multi-aquifer systems.

As a final example of likely open system conditions, Figure 13 shows predicted steady-state lines $\% \mathrm{MC} v$ s. 1/DIC for the case of shallow groundwater, with the direct biogenic input of $\mathrm{CO}_{2}$ deriving from materials ranging in \%MC from 0 to 100 . Fixed parameters are soil $\mathrm{CO}_{2}$ pressure $=0.0035$ atm. (10 times that of present day atmospheric $\mathrm{CO}_{2}$ ); $\% \mathrm{MC}$ of soil $\mathrm{CO}_{2}=115 \%$, temperature $=$ $14^{\circ} \mathrm{C}, \mathrm{k} / \mathrm{k}_{+}=0.0005 \mathrm{mmol} \mathrm{kg}{ }^{-1}$. The lines illustrate that the differing $\% \mathrm{MC}$ values of soil and directly added $\mathrm{CO}_{2}$ combine to produce DIC of intermediate $\% \mathrm{MC}$ value. The abrupt termination of the steady-state lines at the right hand end is a real constraint due to attainment of zero bicarbonate concentration $\left(m_{e}(D I C)=m_{e}\right)$.

Figure 13 contains no data, but it is important because it reveals the true reason for the wide range of ${ }^{14} \mathrm{C}$ concentrations encountered in shallow groundwater.

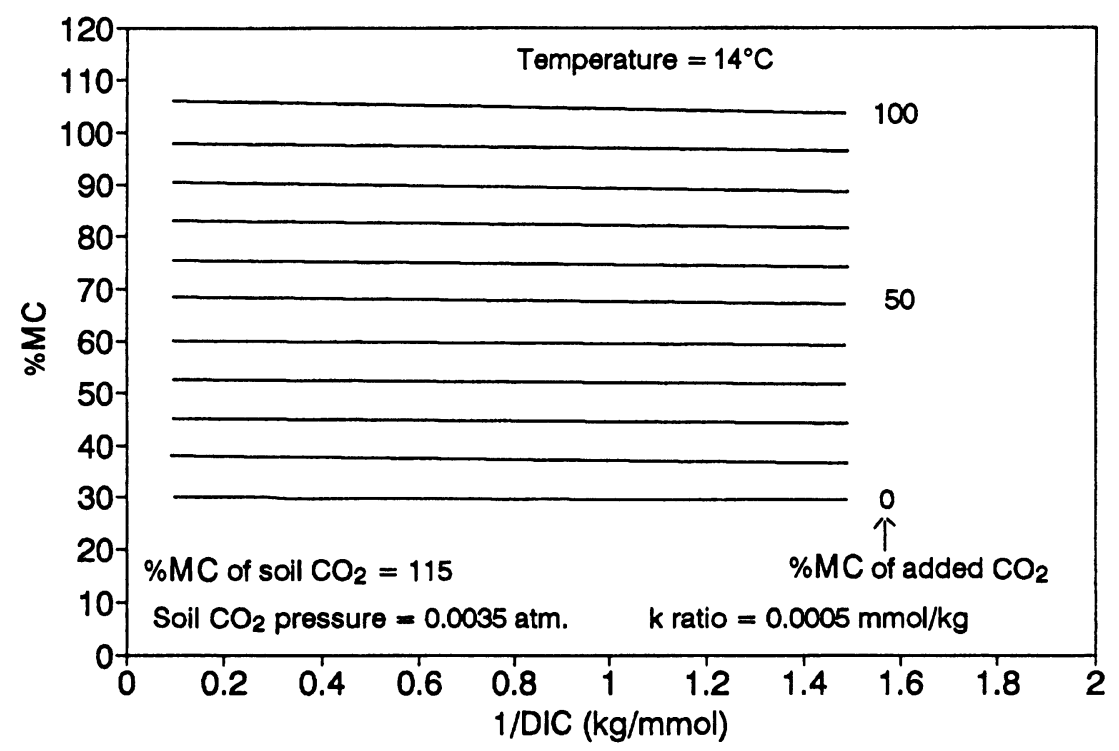

Fig. 13. Steady-state predictions (\%MC vs. 1/DIC) for groundwater samples in an open system (indicated parameters) where the directly added biogenic component has variable $\% \mathrm{MC}$ in the range $0-100$. This variability is primarily responsible for the broad range of ${ }^{14} \mathrm{C}$ concentrations reported in the literature.

\section{CONSEQUENCES OF MODEL FOR GROUNDWATER AGE DETERMINATIONS}

While it can be claimed that this model establishes a valid framework for estimating the isotopic composition of open system DIC for any fixed combination of the relevant parameters, it has to be understood that a known parameter combination is rarely available in any practical application. However, a virtue of the approach is its ability to highlight precisely why it is so difficult to obtain reliable precursor \% $\mathrm{MC}$ values for determination of groundwater residence times for aquifers recharged by precipitation. The crucial open system parameters within any recharge area (soil $\mathrm{CO}_{2}$ pressure, $\mathrm{k} / \mathrm{k}_{+}$ratio, $\% \mathrm{MC}$ of directly added component) are likely to vary over a wide range depending on location (on the scale of meters to tens of kilometers) or season. An accurate, present-day assessment of these parameters and their variations would be extremely difficult in nearly all cases. 
When an attempt is made to tackle the historical variations, the problem becomes even more difficult. Despite this, the results and model framework presented here are a sound basis for practical strategies that should yield useful conclusions about precursor waters and subsequent processes in the closed phase.

The location of recharge areas is often known precisely, but may be identified if necessary by combining hydrogeological evidence with ${ }^{2} \mathrm{H},{ }^{18} \mathrm{O},{ }^{3} \mathrm{H}$, chemical and other measurements on water samples from both the confined aquifers and their likely recharge areas. Some help may be obtained by measurements of pressure and $\delta^{\prime 13} \mathrm{C}$ of soil $\mathrm{CO}_{2}$ in the likely recharge areas, and from any known deposition history of organic materials within the past 50,000 yr.

Measurements of the isotopic composition of DIC in shallow groundwater samples can be inserted into the model diagrams illustrated in this paper. These may then be addressed by the following questions:

- Are the DIC values accurate enough to apply in this way?

- In what area of the $\delta^{\prime 13} \mathrm{C} v$ s. 1/DIC diagram are the samples situated, and what does this reveal about the present open system parameters?

- Does the ${ }^{13} \mathrm{C}$ diagram reveal any evidence of closed rather than open system conditions?

- Do the total ${ }^{14} \mathrm{C}$ contents follow the open-system correlation shown in Figure 11 ?

- Can the distribution of points within ${ }^{13} \mathrm{C}$ or ${ }^{14} \mathrm{C}$ diagrams be tied in sensibly with the closed system data?

- Are any inferences about significant radioactive decay of ${ }^{14} \mathrm{C}$ supported by zero ${ }^{3} \mathrm{H}$ concentrations obtained with adequately low detection limits?

Interpretation is much easier in the case of groundwater recharged directly from rivers without subsequent open-system influence. River samples are easily obtainable, the required parameters for atmospheric $\mathrm{CO}_{2}$ are accessible for both present and historic conditions, and the directly added biogenic component is likely to have a \% MC value similar to that of atmospheric $\mathrm{CO}_{2}$. In this case, the open system total ${ }^{14} \mathrm{C}$ content reference line (Fig. 7) is central to the interpretations, as is good knowledge of the range of isotopic composition $\left(\delta^{\prime 13} \mathrm{C} v s\right.$. 1/DIC) exhibited by the river water under varying flow conditions.

In summary, this combination of model predictions and data diagrams provides a valid framework for application and interpretation of carbon isotopes as tracers of groundwater processes and age.

\section{ACKNOWLEDGMENTS}

I gratefully acknowledge the support of V. J. Fox (GNS tritium laboratory) in achieving accurate quantitative recovery of DIC from our water samples, and the GNS mass spectrometry and AMS teams for ${ }^{13} \mathrm{C}$ and ${ }^{14} \mathrm{C}$ measurements. Field support has been provided by J. Barber (Poverty Bay District Council), K. Baxter (Canterbury Regional Council), G. Bekesi (Manawatu-Wanganui Regional Council), C. Evans (Taranaki Regional Council) and U. Morgenstern (GNS). The Councils mentioned also provided logistic support for field work.

\section{REFERENCES}

Craig, H. 1957 Isotopic standards for carbon and oxygen and correction factors for mass spectrometric analysis of carbon dioxide. Geochimica et Cosmochimica Acta 12: 113-149.

Cheng, S. 1992 Reaction path formulation of a simple dissolution model for radiocarbon dating groundwater. In Long, A. and Kra, R. S., eds., Proceedings of the 14th International ${ }^{14} \mathrm{C}$ Conference. Radiocarbon 34 (3): 646-653.

Coplen, T. B. 1994 Reporting of stable hydrogen, carbon 
and oxygen abundances. Pure and Applied Chemistry 66: 2423-2444.

Drever, J. I. 1997 The Geochemistry of Natural Waters. 3rd ed. Upper Saddle River, New Jersey, Prentice-Hall Inc.: $436 \mathrm{p}$.

Fontes, J.-Ch. and Garnier, J.-M. 1979 Determination of the initial ${ }^{14} \mathrm{C}$ activity of the total dissolved carbon: $\mathrm{A}$ review of the existing models and a new approach. Water Resources Research 15: 399-413.

Geyh, M. A. 1992 The ${ }^{14} \mathrm{C}$ time-scale of groundwater. In Isotopic Techniques in Water Resources Development 1991. Vienna, IAEA: 167-177.

Mook, W. G. 1980 Carbon-14 in hydrogeological studies. In Fritz, P. and Fontes, J.-Ch., eds., Handbook of Environmental Isotope Geochemistry. Vol. 1. Amsterdam, Elsevier Scientific Publishing Co.: 47-74.

Münnich, K. O. 1957 Messung des ${ }^{14} \mathrm{C}$-Gehaltes von hartem Grundwasser. Naturwissenschaften 44: 32-34.

Pearson, F. J., Jr. and Swarzenki, W. V. $1974{ }^{14} \mathrm{C}$ evidence for the origin of arid region groundwater, North Eastern Province, Kenya. In Isotopes in Groundwater Hydrology 1974. Vol. 2. Vienna, IAEA: 95-109.

Plata, A., Baonza, E., and Silgado, A. 1984 Hidrologia isotópica de las aguas subterráneas del Parque Nacional Doñana y zona de influencia. In Isotope Hydrology 1983: Proceedings of an International Symposium on
Isotope Hydrology in Water Resources Development. Vienna, IAEA: 321-340.

Siegenthaler, U. and Münnich, K. O. $1981{ }^{13} \mathrm{C} /{ }^{12} \mathrm{C}$ fractionation during $\mathrm{CO}_{2}$ transfer from air to sea. In Bolin, B., ed., Carbon Cycle Modelling. SCOPE Report 16. Chicester, England, John Wiley \& Sons: 249-257.

Stuiver, M. and Polach, H. 1977 Discussion: Reporting of ${ }^{14} \mathrm{C}$ data. Radiocarbon 19(3): 355-363.

Taylor, C. B. 1994 Hydrology of the Poverty Bay flats aquifers, New Zealand: Recharge mechanisms, evolution of the isotopic composition of dissolved inorganic carbon, and ground water ages. Journal of Hydrology 158: 151-185.

Taylor, C. B. and Fox, V. J. 1996 An isotopic study of dissolved inorganic carbon in the catchment of the Waimakariri River and deep ground water of the Canterbury Plains, New Zealand. Journal of Hydrology 186: 181-190.

Taylor, C. B., Fox, V. J., Brown, L. J. and Bekesi G. (ms.) 1997 Environmental isotopes applied in a study of the hydrogeology of the Manawatu aquifers, North Island, New Zealand. Submitted to Journal of Hydrology.

Taylor, C. B., Wilson, D. D., Brown, L. J., Stewart, M. K., Burden, R. J. and Brailsford, G. W. 1989 Sources and flow of North Canterbury Plains ground water, New Zealand. Journal of Hydrology 106: 311-340. 